\title{
Dissolved oxygen and water temperature dynamics in lowland rivers over various timescales
}

\author{
Agnieszka Rajwa-Kuligiewicz , Robert J. Bialik, Paweł M. Rowiński \\ Institute of Geophysics, Polish Academy of Sciences, Centre for Polar Studies, Ks. Janusza 64, 01-452 Warsaw, Poland. \\ ${ }^{*}$ Corresponding author. E-mail: arajwa@igf.edu.pl
}

\begin{abstract}
The impact of floodplain hydrology on the in-stream dissolved oxygen dynamics and the relation between dissolved oxygen and water temperature are investigated. This has been done by examining the time series of dissolved oxygen and water temperature coupled with meteorological and hydrological data obtained from two lowland rivers having contrasting hydrological settings. Spectral analysis of long-term oxygen variations in a vegetated river revealed a distinct scaling regime with slope ' -1 ' indicating a self-similar behaviour. Identical slopes were obtained for water temperature and water level. The same power-law behaviour was observed for an unvegetated river at small timescales revealing the underlying scaling behaviour of dissolved oxygen regime for different types of rivers and over various time scales. The results have shown that the oxygenation of a vegetated river is strongly related to its thermal regime and flow conditions. Moreover, analysis of short-term fluctuations in the unvegetated river demonstrated that physical factors such as rainfall and backwaters play a substantial role in the functioning of this ecosystem. Finally, the results show that the relation between water temperature and dissolved oxygen concentration at the diurnal timescale exhibits a looping behaviour on the variable plot. The findings of this study provide an insight into the sensitivity of rivers to changing hydro-physical conditions and can be useful in the assessment of environmental variability.
\end{abstract}

Keywords: Dissolved oxygen; Water temperature; Hysteresis; Spectral analysis; Self-similarity; Anastomosing river; Backwaters.

\section{INTRODUCTION}

Dissolved oxygen (DO) is one of the most important indicators of the biological health of rivers exhibiting large fluctuations over a wide range of spatial and temporal scales. It is primarily dependent upon water temperature; however, this dependence undergoes alterations due to changing hydrometeorological conditions (Rajwa et al., 2014) and the intensity of biological processes such as photosynthesis, respiration and decomposition of organic matter.

The selection of temporal scale of these fluctuations may usually lead to different conclusions with respect to the dynamics of the process under study. For example, monitoring programs provide a valuable insight into the structure and functioning of the ecosystems, however, the sampling frequency of this monitoring is often insufficient to evaluate the impact of shortterm impulses on hydrochemical components (Halliday et al., 2012; Neal et al., 2013; Wade et al., 2012). As pointed by Gnauck et al. (2010) at greater timescales ( $>1$ week) the DO dynamics are primarily driven by the low-frequency behaviour of water temperature and thus, sharp changes in DO concentrations cannot be captured by conventional monitoring systems.

In fact, the long term data sets are related to the shorter ones by the same scaling law and it seems reasonable to apply the method that integrates the changes over long and short timescales. So far, spectral analyses have been widely used in various areas of science and engineering. Less attention has been paid to its application in water chemistry dynamics (e.g., Feng et al., 2004; Kirchner and Neal, 2013; Kirchner et al., 2000, 2001), whereas only few studies have examined spectral characteristics of DO concentration time series (e.g., Facchini et al., 2007; Frieder et al., 2012; Huang and Schmitt, 2014; Schmitt et al., 2008). The limited number of studies is associated with a high rate of missing values in monitoring data bases resulting from routine maintenance, inaccessibility or occasional failures of measuring devices (Schmitt et al., 2008). Despite these drawbacks, the interpretation of spectral properties of water chemistry remains a challenge to the fundamental understanding of processes in fluvial systems. Our study aims to show that spectral analyses may not only be a useful tool in the analysis of long time series but also a good way to relate long and short term measurements within the same scaling laws.

Addressing these issues a comparative field study on two rivers has been undertaken in order to (i) quantify the fluctuations of DO concentrations across the monitoring periods, (ii) examine hydrologic controls on temporal variations in DO concentrations, (iii) identify and analyse different patterns of water temperature and DO relation in rivers. Particularly, we focused on the effects of hydrological variability and antecedent hydrologic conditions on water oxygenation. Finally, we tried to determine how hydrologic processes contributed to the oxygen variability and assessed the role of individual factors such as rainfall or backwaters and processes affecting water temperature and DO relation.

\section{METHODS \\ Study sites description}

Field studies have been carried out in the Świder and Narew Rivers in Poland, which have been chosen deliberately due to the contrasting hydrological settings and vegetation cover. The differences between those rivers are also related to the oxygenation level. The Świder River is a well oxygenated river making it ideal for studying the response to external inputs, whereas the Narew River is sensitive to oxygen depletion and thus, is suitable for study the impact of vegetation.

The Narew National Park located in Northeast Poland protects a unique ecosystem of an anastomosing river, which encompasses the area of the river valley between the towns of Suraż and Rzędziany (Fig. 1). The river is characterised by the 
irregular network of small river channels and oxbows separated by inter-channel areas stabilised by densely vegetated banks. Around $90 \%$ of the Park's area constitutes either swamps of standing water or slowly moving waters of the Narew River. The climate of this area shows continental features with high amplitudes of annual temperatures, the longest period of ice cover, compared with other Polish rivers, and a relatively short vegetation period. The area of swamps is subjected to annual flooding from the beginning of March until May, rarely until June (Banaszuk, 1996). As a result, the input of terrestrial organic matter (mainly humus compounds) from these events plays an important role in supporting aquatic heterotrophy. The Narew River is supplied essentially by groundwater during summer season and is dominated by substantial quantities of submerged and floating plants canopy. The width of channels usually varies from a few metres to $30 \mathrm{~m}$, whereas the depth ranges from 1.5 to $3 \mathrm{~m}$ in the smaller channels up to $4-5 \mathrm{~m}$ in the main river channel (Gradziński et al., 2000). The river has a sandy bed consisting of medium and coarse sand (Gradziński et al., 2003). Owing to the small slope and presence of aquatic vegetation generating high drag forces, the current is reduced and mean velocities at the normal flow conditions rarely exceed $0.35 \mathrm{~m} \mathrm{~s}^{-1}$ (Gradziński et al., 2003).

In this study, we used the data from a water quality monitoring network in Kruszewo Village (Fig. 1) located in the Narew National Park. It should be noted that this monitoring network provides very useful data base, however, it has never been applied for scientific purposes.

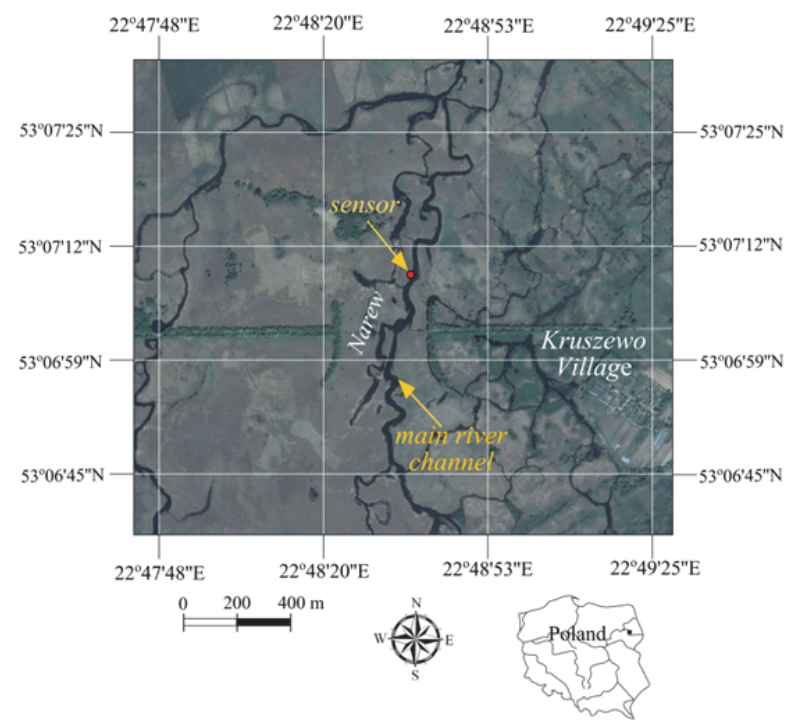

Fig. 1. Study site location - the Narew River.

The Świder River is a typical meandering river, right tributary of the Vistula River. The river has a length of $99 \mathrm{~km}$ and its catchment covers $1161 \mathrm{~km}^{2}$ (IMGW 1983). The Świder River is of natural character, its bed consists of coarse and medium sand forming numerous bed forms such as dunes and ripples. The river is relatively shallow with a fast current. The study site was located in Świder village situated approximately $20 \mathrm{~km}$ south of Warsaw (Fig. 2).

\section{Data collection}

In order to identify factors responsible for seasonal and temporal variations of dissolved oxygen, we compared two datasets collected at two different time steps: a 1-hour time interval for the Narew River and a 5-minute time interval for the Świder

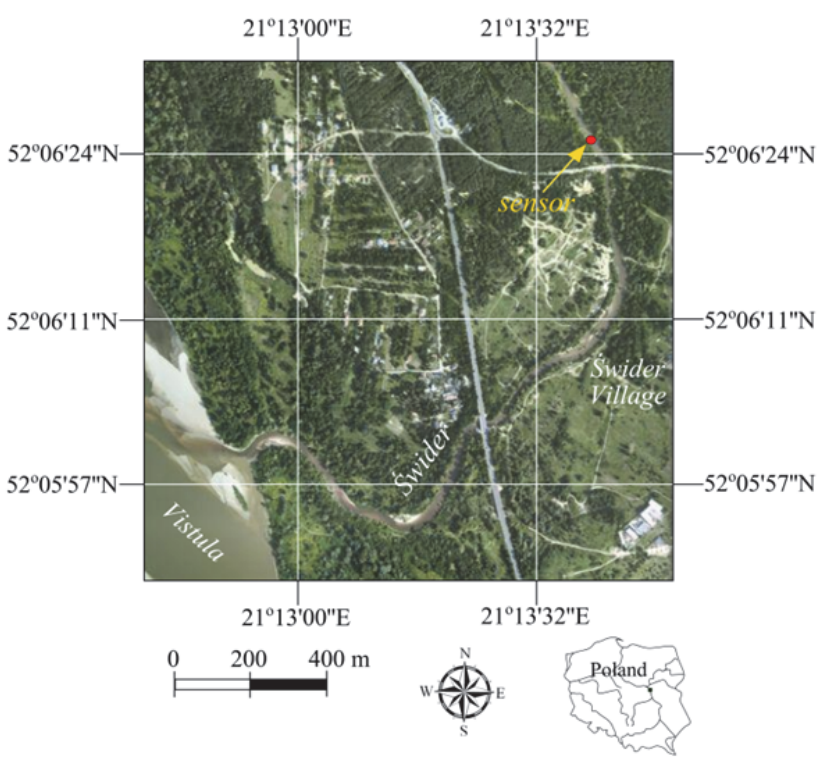

Fig. 2. Study site location - the Świder River.

River. In both investigations optical sensors of DO having the accuracy of $\pm 0.1 \mathrm{mg} / \mathrm{L}$ (in the range of $0-20 \mathrm{mg} / \mathrm{L}$ ) were used.

The measurements in the Narew River were conducted in the main river channel using a multi-parameter sonde (manufactured by Hydrolab Omnidata Systems, London, UK). The retrieved data from the Narew River cover a period of almost 2.5 years (from 02.02.2012 to 30.10.2014) with spikes and gaps resulting from routine maintenance, and failures of the measuring device (Fig. 3). Missing values constitute as much as 19\% of the total records but they are luckily quite heterogeneously distributed in time series. For the purpose of this study, all the data were threated collectively as we cannot be sure whether outliers were caused by natural perturbations. Since no other DO concentration data is available from the other sites, it is suggested that the data used in this study is valid only for this particular site.

In the Świder River three campaigns covering from two to four days of continuous measurements were carried out at the end of May 2014 (from the 21st to 24th), at the beginning of July 2013 (from 9th to the 11th) and at the end of September 2013 (from 25th to 27th). Dissolved oxygen, water temperature and air pressure were recorded using a ProODO meter (manufactured by YSI, Yellow Springs, USA). The instrument was calibrated prior to deployment at $100 \%$ water saturated air and placed at a medium depth in the middle of the river channel.

Hydrological and meteorological data for both study sites were provided by the meteorological station of the Institute of Geophysics, Polish Academy of Sciences and by the Institute of Meteorology and Water Management (IMGW). Discharges and water levels in the Narew River were obtained from the gauge, whereas the discharge of the Świder River was measured each day of measurements using the ADCP (the Acoustic Doppler Current Profiler, RiverSurveyor S5, manufactured by SonTek).

\section{Data analysis}

In order to characterise the variability of DO and water temperature, time series have been studied through the power spectral density (PSD). Spectral analysis performed using a Fast Fourier Transform (FFT) algorithm is widely used in environmental studies, because it reveals the dominant influences and their scales. The primary advantage of this method lies in frequency 


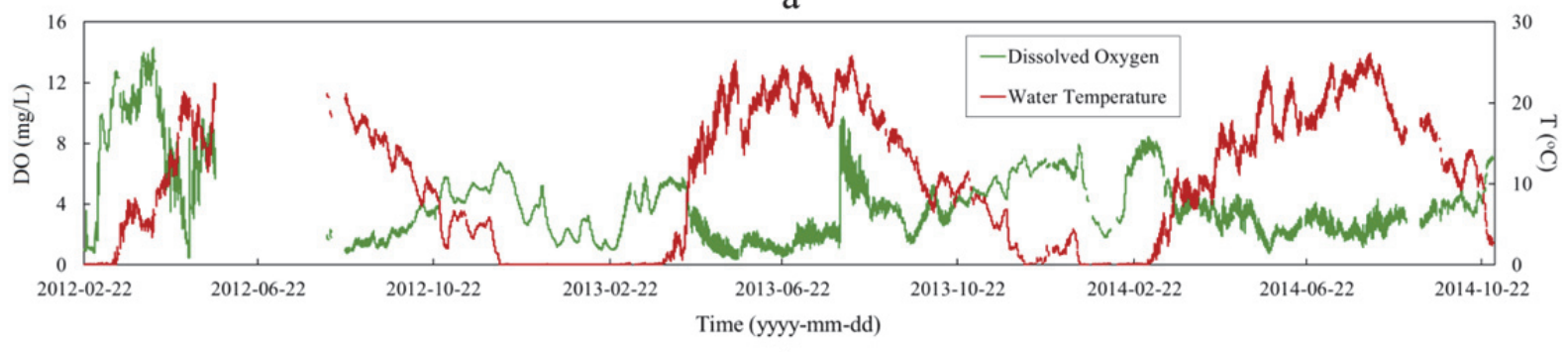

b

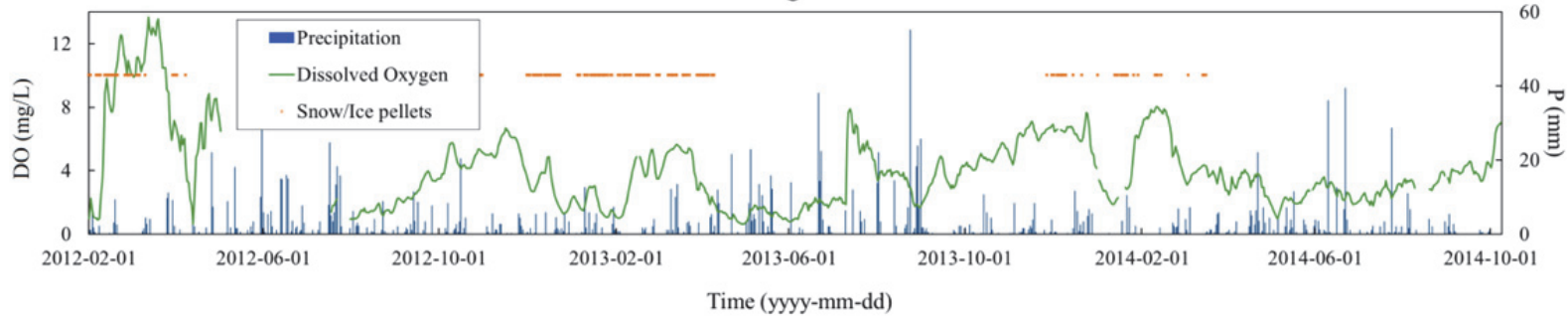

c

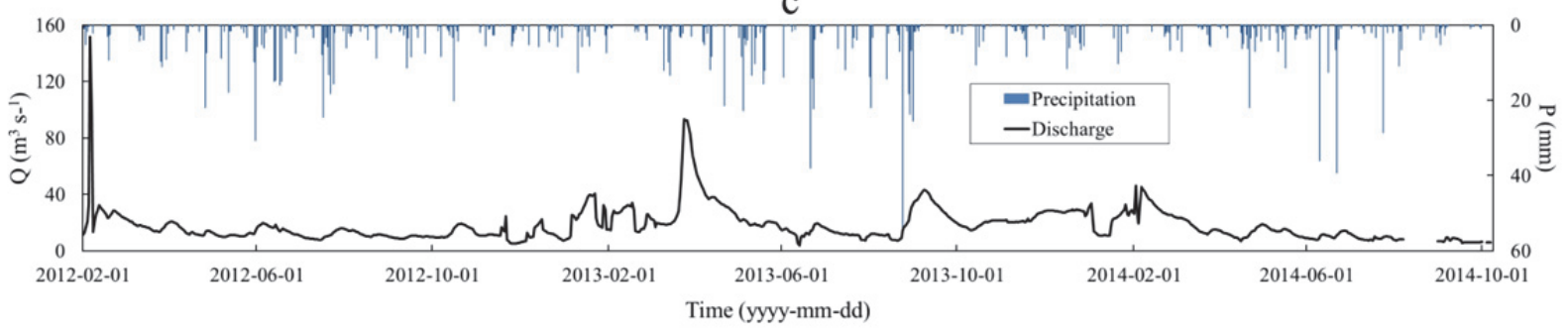

Fig. 3. Time series of dissolved oxygen concentration and water temperature in the Narew River (a), daily mean dissolved oxygen, daily precipitations and snow events (b), daily mean discharge $(Q)$ and daily precipitation $(P)(\mathrm{c})$.

domain metrics, which are the most useful indices for the assessment of DO dynamics and parameterisation of environmental variability. As pointed out by Witt and Malamud (2013) spectral analyses are helpful not only in detecting periodicities but also evaluating persistence in time series. In our work, a special attention is paid to identifying spectral scaling ranges, i.e., ranges of scales over which log-log linearity is observed in the PSD. We do realise that some deeper analysis can be achieved with the use of wavelet transform but it goes beyond the scope of this paper and will be presented elsewhere. The main difference is that wavelets are localised in both time and frequency, whereas the standard Fourier transform is only localised in frequency.

Due to the fact that FFT requires continuously sampled data, it is necessary to obtain the estimates of the missing values. To date, a variety of strategies have been proposed to handle with missing values, either smoothing the data or interpolate the missing values. In case of large gaps and unevenly sampled data, it is also advisable to use other than FFT techniques such as the Lomb-Scargle periodogram (Hocke and Kämpfer, 2009), the Hilbert-Huang transform (Huang and Schmitt, 2014) or the Kirchner's filtering method (Kirchner, 2005).

In our study the power spectrum was computed by means of 'fast Fourier transform' algorithm available in Matlab. In case of short time series obtained from the Świder River, all data were available and thus, the FFT was applied directly to time series. In case of long time series with missing values collected in the Narew River, a period from 22 August 2012 to 30 August 2014 was selected and a cubic interpolation was done in order to fill the gaps of time series. This period of time contains 16074 evenly sampled records with $10 \%$ of missing values. It should be noted, however, that the data interpolation we used may cause the distortions of the power spectra. Also, the spectral slope obtained in this way may be biased toward lower values.

\section{RESULTS}

The results are divided into two parts. The first part shows seasonal variations of DO and the relation between water temperature and dissolved oxygen concentration over a three-year period in the Narew River. The second part analyses the relation between water temperature and dissolved oxygen in the Świder River at short timescales. Herein, the attention is paid to the influence of single hydrological events, such as rainfall and backwaters on DO conditions.

\section{DO dynamics at long timescales}

Figure 4 presents the relation between water temperature and dissolved oxygen concentration recorded in the Narew River for particular years: 2012 (red), 2013 (green) and 2014 (blue). The location of points below the red dashed line $\left(\mathrm{DO}_{\text {sat }}\right)$ representing oxygen solubility dependence on temperature (calculated according to the formula derived from the Committee on Sanitary Engineering Research, 1960) implies that the Narew River is dominated by strong oxygen deficit over the year. This figure also suggests that the annual trend of DO concentrations is closely related to the thermal regime of the river and that recorded values without outliers can be roughly approximated with a 3rd order polynomial $\left(\mathrm{DO}_{\mathrm{fit}}\right)$. Moreover, the wide scattering of points suggests that the impact of certain factors such 
as the recharge from snow melting, groundwater inputs and rainfall events varies substantially from one year to another. These processes are usually non-stationary, and distributed across various time scales. However, neither precipitation, nor discharge has a statistically significant relationship with daily mean DO concentrations (Fig. 5). The indirect impact of these factors is primarily caused by the complexity of interactions within river channels and adjacent wetlands.

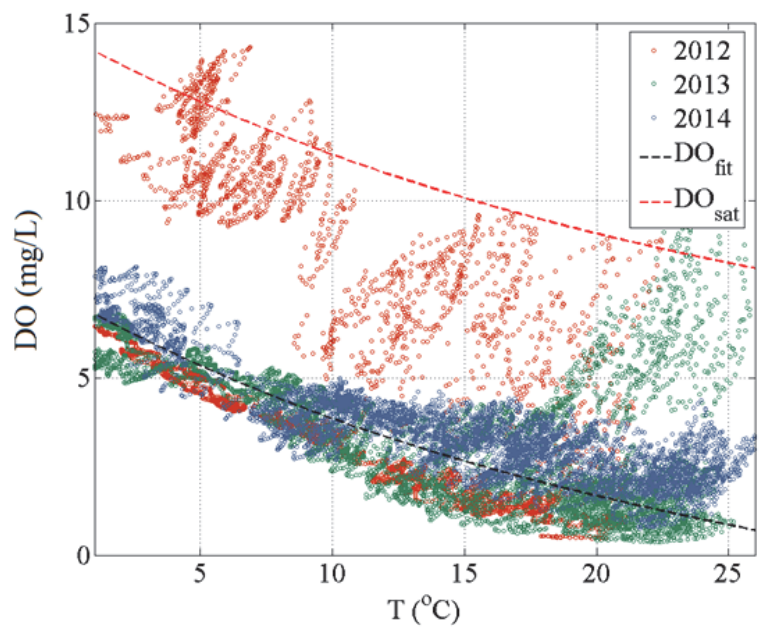

Fig. 4. Scatter plot of DO vs. water temperature from 3 years of measurements in the Narew River compared with oxygen solubility dependence on water temperature represented by the red dashed line $\mathrm{DO}_{\text {sat }}$ (please note, $\mathrm{DO}_{\text {sat }}$ line does not take into account the changes in atmospheric pressure). The black dashed line $\left(\mathrm{DO}_{\mathrm{fit}}\right)$ was fitted to the recorded DO concentrations.

The DO level gradually decreases from winter to the summer months (Fig. 6), concurrently, increasing its diurnal fluctuations. In the summer, diurnal changes are related to the higher rate of biological activity as it increases exponentially with temperature (Brown et al., 2004). As pointed by Desmet et al. (2011), biological processes such as photosynthesis, respiration and remineralisation of organic matter significantly affect oxygen levels in lowland rivers and are responsible for high diurnal variations in DO concentrations, even up to $5.0 \mathrm{mg} / \mathrm{L}$. However, the intensified biological activity when combined with morphological characteristics of the river such as the presence of stagnant waters, contributes to the occurrence of hypoxia $(\mathrm{DO} \leq$ $2 \mathrm{mg} / \mathrm{L}$ ). Hypoxic periods are often associated with the imbalance between biological processes of aquatic biota resulting

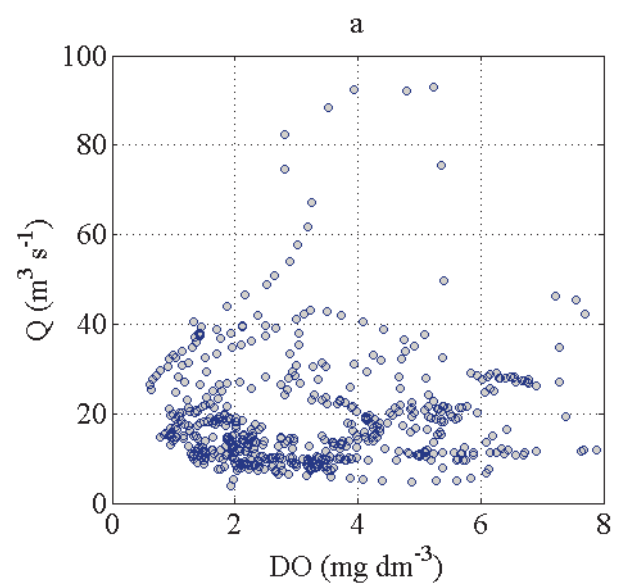

from transport processes, availability of dissolved substances and particles (Demars et al., 2011; Pena et al., 2010). For example, the oxygen deficiencies in the Narew River often emerge from the decomposition of organic matter and the limited rate of photosynthesis due to low water transparency, which is especially visible during summer low flows. Moreover, the mineralisation of organic detritus retained in the river bed coupled with dissolved organic carbon (DOC) contained in the water column leads to drops in dissolved oxygen concentrations and subsequent increase of phosphorus release from bottom sediments (Banaszuk and Wysocka-Czubaszek, 2005). The hypoxic events can also be attributed to the changes in plant morphology as the leaves can limit the diffusion of oxygen to the bottom layers (Goodwin et al., 2008). On the other hand, hypoxic conditions might be also an indicator of significant groundwater inputs in summer or the formation of ice cover in winter (Whitfield and McNaughton, 1986).

Finally, it is worth noting that the annual relation between water temperature and DO gives us just some kind of approximation of river oxygenation resulting from the changes of thermal regime and thereby, in a great simplification, comes down to the oxygen solubility dependence on water temperature. Nonetheless, the problem arises when identifying other physical factors beyond water temperature responsible for DO variations across a wide range of timescales.

Figure 7 displays the probability density of DO concentration indicating moderate right skewed $(\gamma=0.51$, where $\gamma$ is skewness) leptokurtic ( $k=2.57$, where $k$ is kurtosis) distribution with mean 3.55 , median 3.38 and a standard deviation of 1.75. The asymmetric distribution of DO concentrations is rather expected as the water quality data usually do not follow Gaussian distribution (Lettenmaier et al., 1991).

The results of spectral analysis indicated the background power-law regime (dashed line) for DO concentrations: $P(f) \propto f^{-\alpha}$ where $\alpha=-1.0$ spreads over four orders of magnitude (Fig. 8a). Moreover, one distinctive peak associated with deterministic forcing is easily recognised in the power spectrum of DO (Fig. 8a) and water temperature (Fig. 8b) corresponding to the day-night cycle. In contrast to water temperature power spectrum, where the annual peak can be roughly distinguished between the frequencies of $10^{-3}$ and $10^{-2}$, in the DO power spectrum no annual cycle is displayed.

The value close to -1.0 shows a power-law scaling that resembles $1 / \mathrm{f}$ noise known as the pink noise. For this noise, power spectral density decreases proportionally to the inverse of the frequency pointing on self-similarity phenomenon. Moreover, it implies a long-term memory of the system with a self-

b

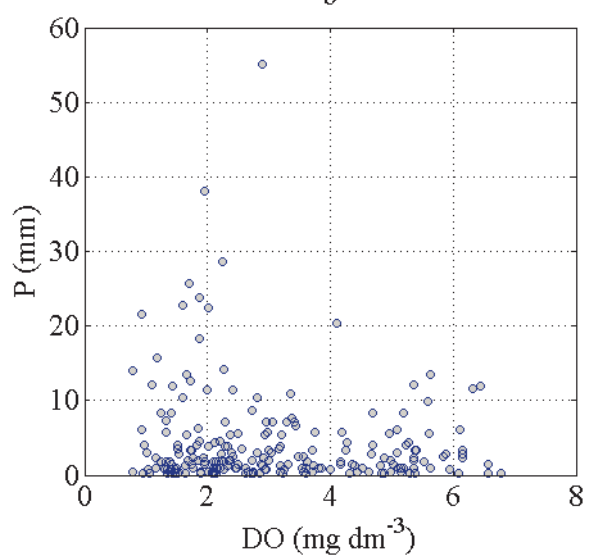

Fig. 5. Scatterplots: (a) mean daily DO concentrations in the Narew River vs. river discharge; (b) mean daily DO concentrations vs. precipitations. 

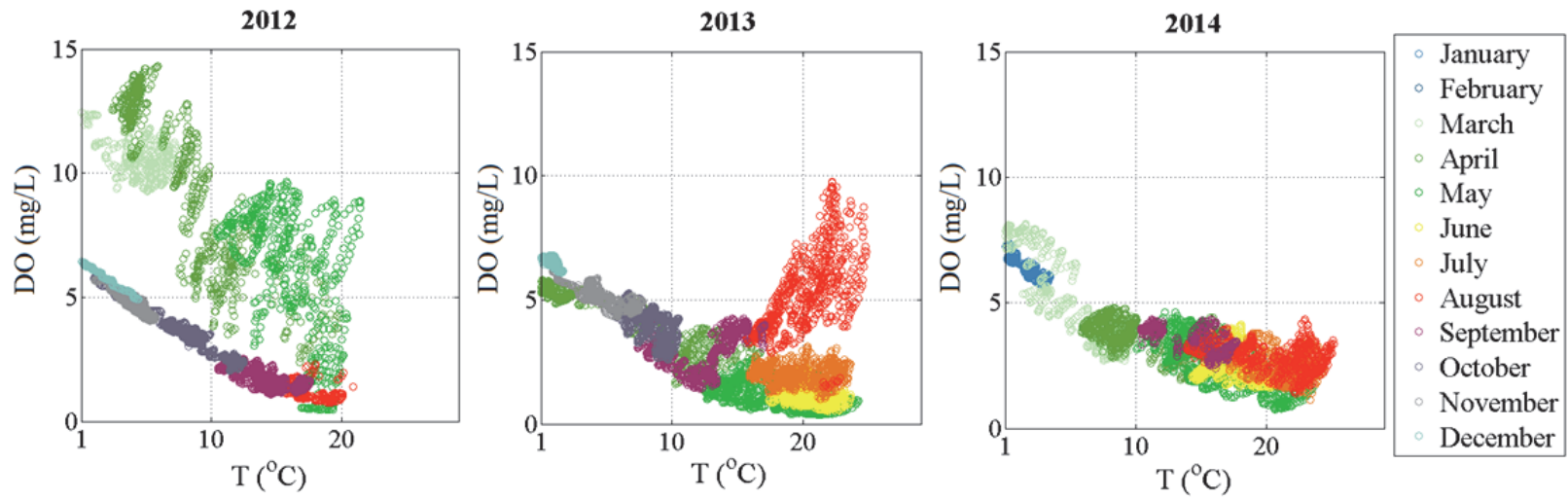

Fig. 6. Scatter plots of DO and water temperature in the Narew River for particular months of the given years.

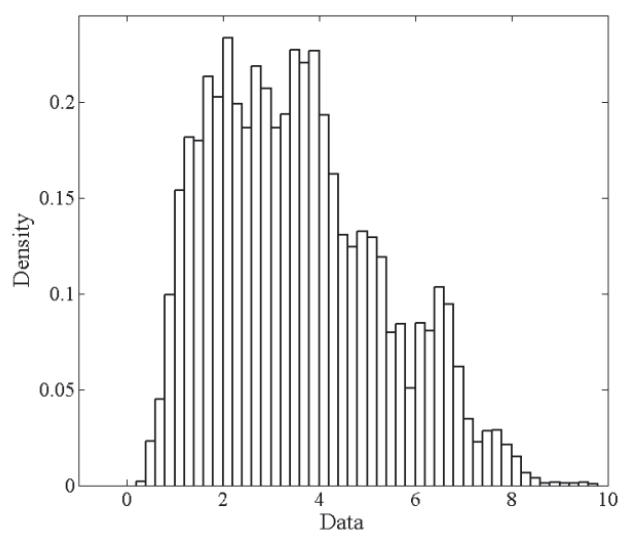

Fig. 7. The probability density of the DO concentration data (the Narew River).

stabilising mechanism. The term 'self-similarity' was originally introduced by Mandelbrot (1967) while dealing with fractal objects in a wide variety of physical contexts. Self-similarity has turned out to be an inherent feature of many natural phenomena starting with coastline shape, earthquakes, river networks (Turcotte, 1997), ending with the Kolmogorov's $-5 / 3$ spectrum of turbulent velocity correlations (Kolmogorov, 1941) and fractal stream chemistry (Kirchner et al., 2000). In the power spectra this property manifests in a decaying autocorrelation function that is inversely proportional to the frequency. Self-similarity manifests itself in water quality studies in a number of ways. A good example are the concentration-time profiles at a river site which might appear as self-similar over a wide range of flows, therefore there are ways to express them in non-dimensional form so that they collapse on to a single profile (Wallis, 2005). According to Kirchner et al. (2001) and Kirchner and Neal (2013), the noise $1 / \mathrm{f}$ in water quality reflects natural processes such as transport of dissolved substances and ions, dispersive mixing of solutes and storage in the catchment.

The obtained slope of dissolved oxygen is consistent with the slopes of water temperature and water level (Figs 8b, 9a), whereas precipitations can be roughly approximated as white noise (Fig. 9b). To compare, Yu (2006) obtained the same slope for water level in peatlands. For DO saturation values Schmitt et al. (2008) obtained the background power-law regime with slope -1.22 . Likewise, the presence of white noise in precipitation time series has been reported by Delworth and Manabe (1993). It should be noted however, that the rainfall time series may exhibit different spectral characteristics for storms and seasonal precipitations (Matsoukas and Islam, 2000). General- ly, for white noise time series, spectral power is constant with frequency and the series are self-averaging meaning that averages converge to a stable mean. As a result, the short-term behaviour in white noise time series is entirely unpredictable whereas long-term behaviour is predictable.

One of the most essential facts resulting from self-similarity is that the analysis of $\mathrm{DO}$ at different timescales provides the same qualitative picture and the signal-to-noise ratio is actually independent of the chosen timescale. Notably, the seasonal cycles of DO concentrations are indirectly considered by investigating changes at diurnal timescale as they superimposed upon the diurnal cycles. Thus, one may equally analyse DO fluctuations at small timescales. In fact, the short-term behaviour in pink noise time series is entirely unpredictable. On the other hand, due to the persistence of long-term drift, the longterm behaviour becomes highly unpredictable.

To illustate this point, we have performed a Fourier transform on a four-day period of time. Figure 10a shows time curves of DO and water temperature covering four days of measurements. To compare, the relation between water temperature and DO is presented in Fig. 10b. Corresponding power density spectra of DO and water temperature is given below (Fig. 11). Please note that the slopes are consistent with those from the entire dataset. Moreover, the peak at the frequency of one day is visibe in the PSD of dissolved oxygen.

The situation becomes more complicated if we consider only short periods of time. According to Feng et al. (2004) three types of distortion can arise when analysing shorter periods of high-frequency sampling during episodes: first type results from the fact that the behaviour during episodes is not typical and thus it may generate the bias, second type is usually attributed to the smaller than twice the Nyquist frequency sampling rate generating aliases, and the third one is related to the interpolation of such records, which artificially bias the spectral power towards lower values at short wavelengths. This will be discussed more extensively in the next paragraph.

\section{DO fluctuations at short timescales}

Having demonstrated that long time series give the same qualitative picture as short time series, we aimed at evaluating the impact of hydraulic factors on DO fluctuations in another river. The impact of changing hydraulic conditions on oxygen concentrations is difficult to assess due to its temporal character. Therefore, it can only be analysed at frequencies smaller than hours and in rivers where plant activity can be either partially or completely neglected like in the Świder River. An exception is made for algae as they are a natural part of the fresh- 

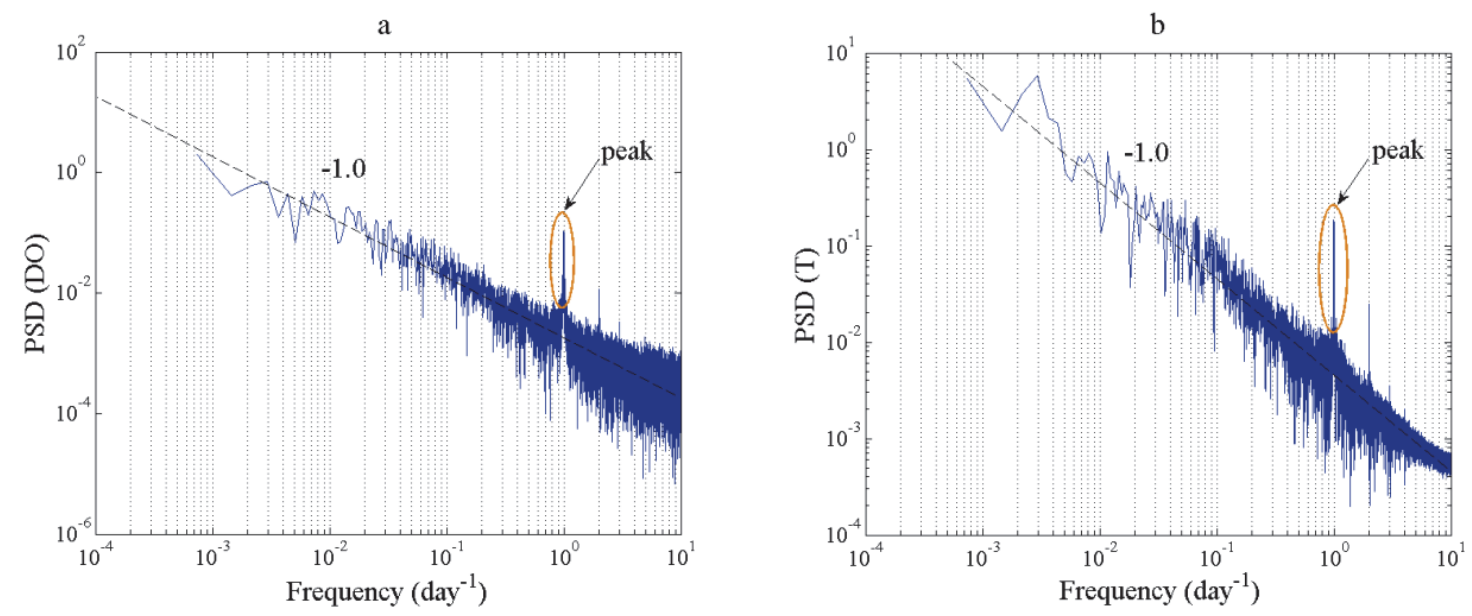

Fig. 8. The power spectral density (the Narew River): (a) DO concentrations, (b) water temperature. Power spectral density (PSD) is given as a function of frequency as plotted in a $\log -\log$ scale.
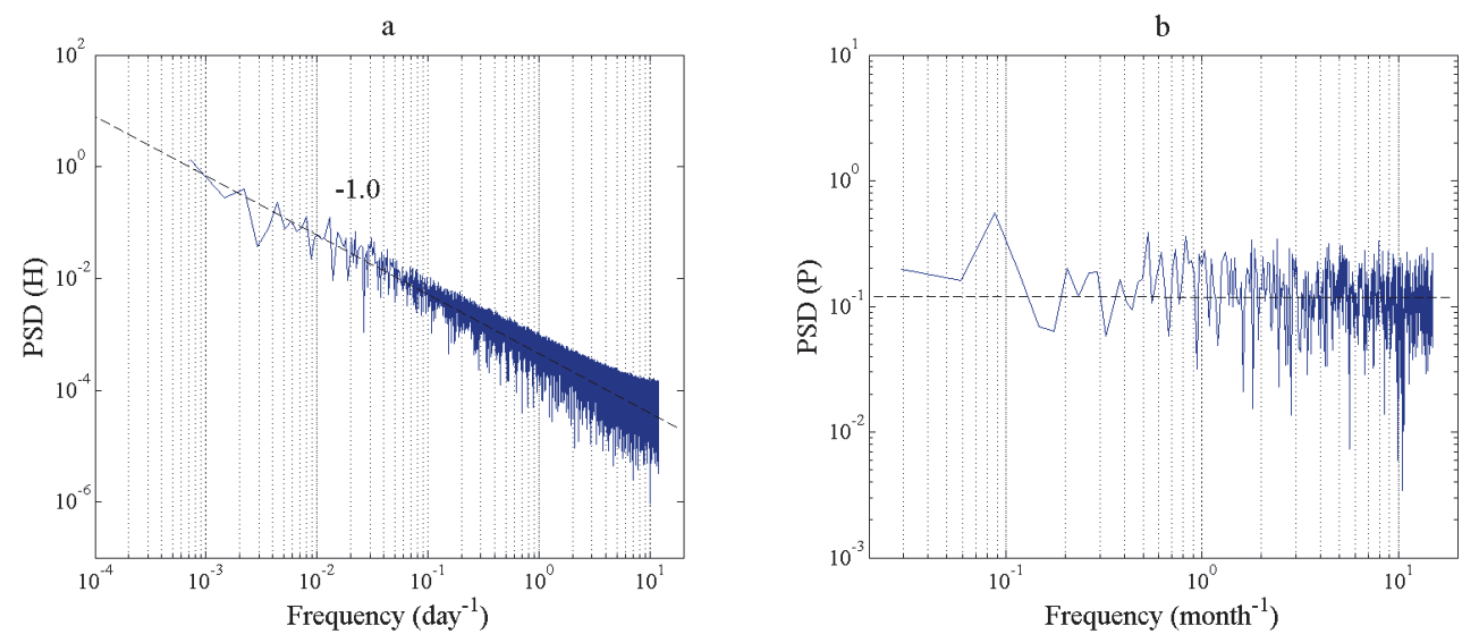

Fig. 9. The power spectral density (the Narew River): (a) water level, (b) daily precipitations in log-log plot.
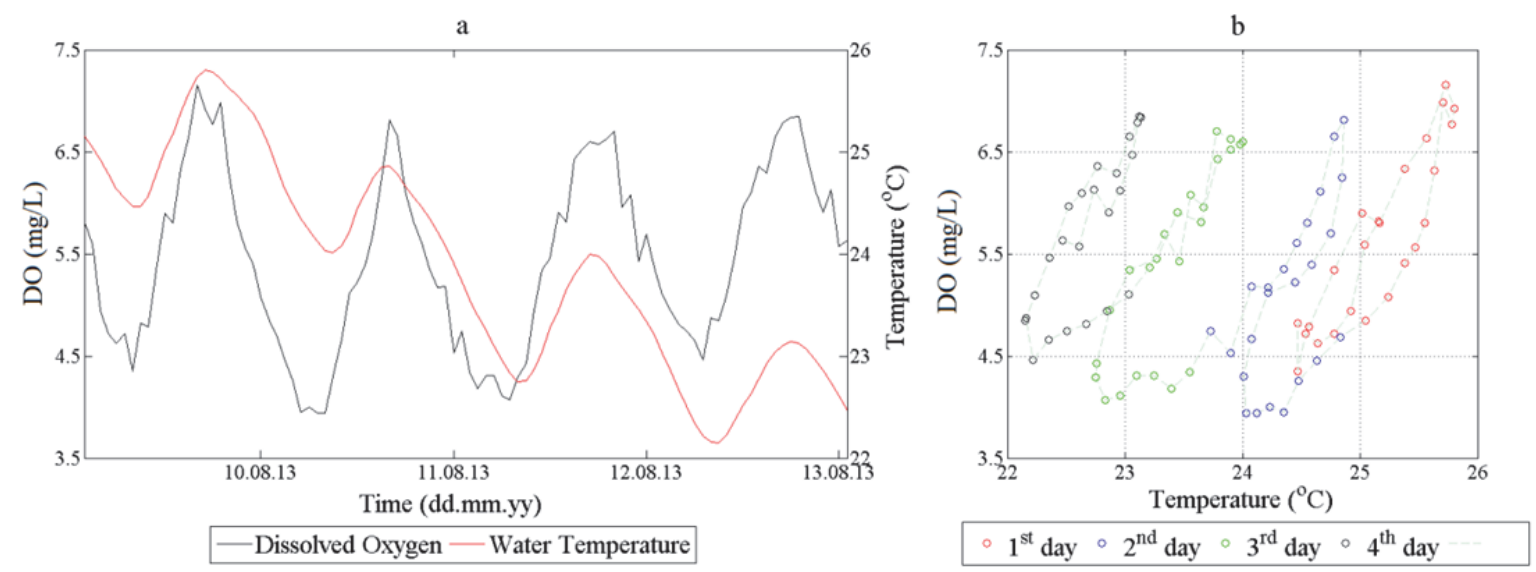

Fig. 10. Time series of DO and water temperature from the Narew River (a); the scatterplot of DO vs. water temperature (b).

water environment, especially under low flow conditions (Demars and Harper, 1998, 2005).

The measurements in the Świder River were conducted in May under backwater conditions (a), in July under sunny weather (b) and in September under rainfall (c).

The hydrological characteristics of the river during the days of measurements are summarised in Table 1. Figure 12 portrays the relation between water temperature and oxygen concentra- tion for these periods of time. Corresponding oxygen clocks showing each day at a single graph are presented in Fig. 13. In contrast to the standard time curves, they highlight the diurnal cycle and facilitate the comparison of multiple days.

It is visible in Fig. 12 that points connected in time order exhibit some looping behaviour, which could not be recognised at greater timescales. The presence of a hysteretic loop means that for any given water temperature, there are two or even more 

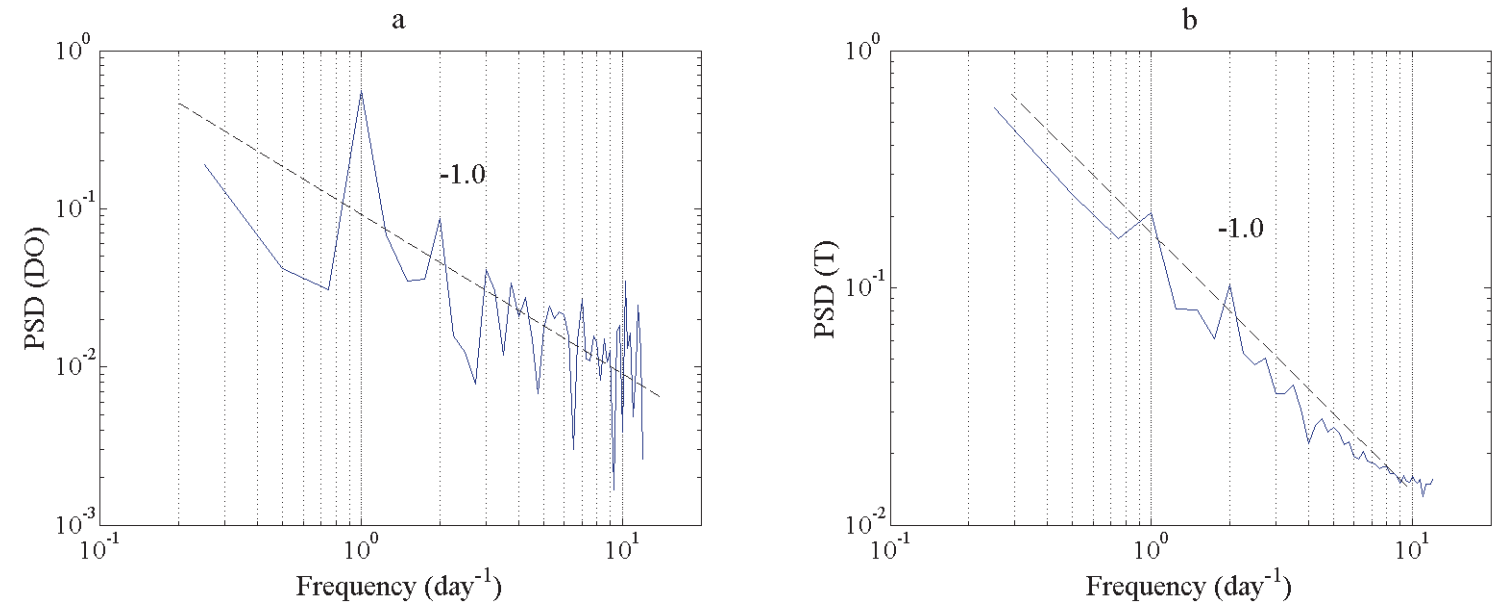

Fig. 11. The power spectral density (the Narew River): (a) dissolved oxygen, (b) water temperature in log-log plot.
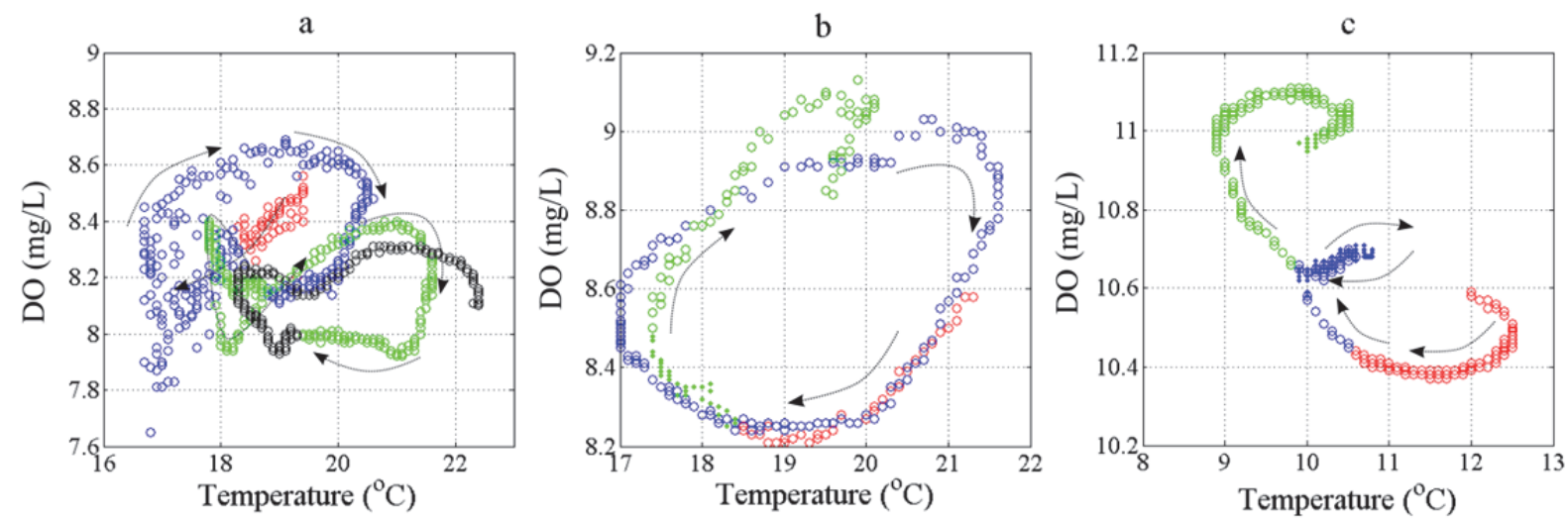

$\circ 1^{\text {st }}$ day $\circ 2^{\text {nd }}$ day ${ }^{\circ} 3^{\text {rd }}$ day $\circ 4^{\text {th }}$ day

Fig. 12. Scatter plots of DO vs. water temperature for the Świder River: (a) May 2014, (b) July 2013, (c) September 2013. Please note that scatterplots are arranged in a seasonal order.
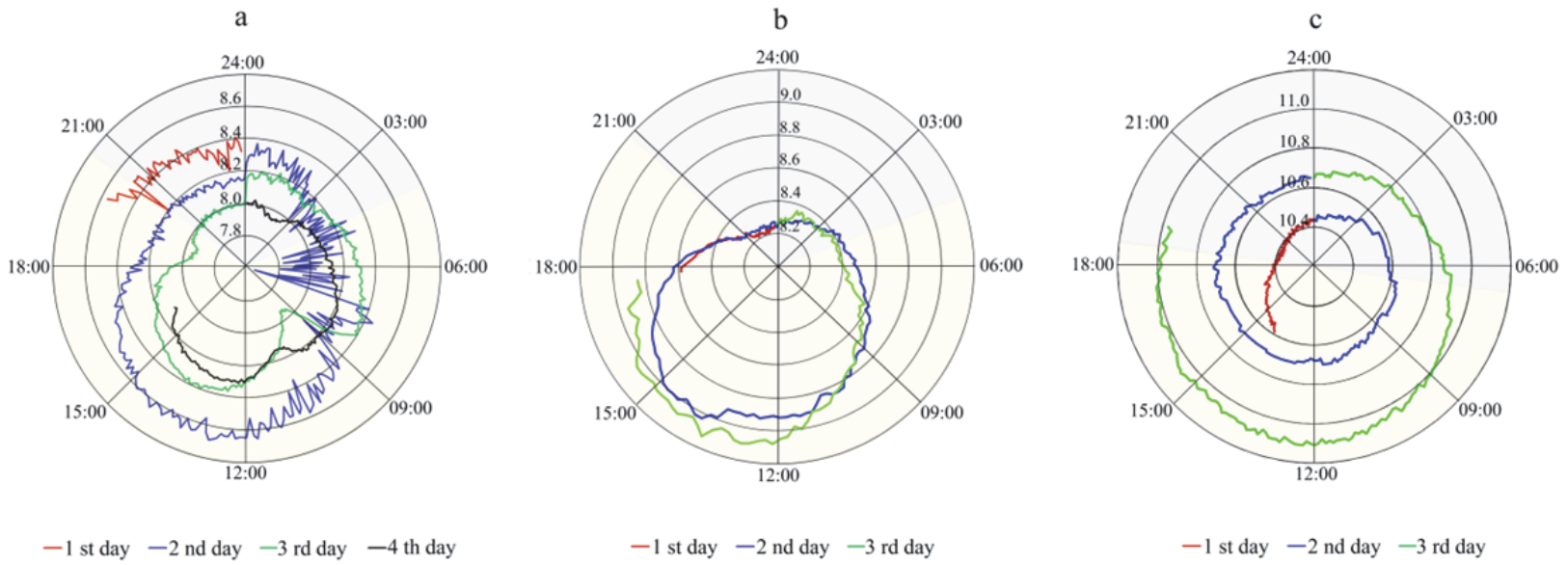

Fig. 13. Oxygen clocks for the Świder River: (a) May 2014, (b) July 2013, (c) September 2013.

levels of oxygen concentration, which is visible on the upswing and downswing curves. In Fig. 12b the loop is closed and has a regular shape. This loop proceeds clockwise and occurs in periods of stable sunny weather and steady flow. The hysteresis is likely a light-driven photosynthesis of algae as the change in oxygen concentrations precedes the change in temperature.
In comparison, in the Fig. 12c all loops are open, which results from consecutive rainfalls: $3.8 \mathrm{~mm}, 2.5 \mathrm{~mm}, 4.2 \mathrm{~mm}$ respectively.

Notably, backwaters disturb the relation between DO and T (Figs 12a, 13a). It should be stressed that the sensor was placed deliberately at the site directly influenced by backwaters. 
Table 1. Hydraulic characteristics of the Świder River during the days of measurement; a, b and c represent backwater, sunny weather and rainfall conditions, respectively.

\begin{tabular}{lll}
\hline Case & $Q\left(\mathrm{~m}^{3}\right)$ & $V_{a v}\left(\mathrm{~m} \mathrm{~s}^{-1}\right)$ \\
\hline $\mathrm{a}$ & 4.0 & 0.17 \\
$\mathrm{~b}$ & 3.0 & 0.50 \\
$\mathrm{c}$ & 3.1 & 0.50
\end{tabular}

$Q$ - water discharge, $V_{a v}$ - average velocity in the river cross-section

Despite the weather being fine and stable during backwater, the water level had been decreasing rapidly from 21 May. The obtained results are in accordance with Flinn et al. (2008) who noted that backwaters directly and indirectly affect the biological communities in off-channel habitats. However, the disturbances in oxygen concentration could also be initiated during the storm preceding the backwater. As pointed by O'Connor et al. (2012) storms lead to bed disturbances and increase turbidity, which eventually disrupt stream metabolism. Moreover, as was reported in other studies, characteristics of these abiotic factors, particularly the timing, frequency, magnitude, duration and rate of change of hydrologic conditions shape riverine communities (Bayley, 1991; Junk et al., 1989; Poff and Ward, 1989; Poff et al., 1997).

Finally, it is easy to note, that spectral analyses performed for the diurnal time series collected at short time steps have shown the existence of the same scaling range with the exponent ' -1 ' (Fig. 14). However, in order to confirm the universality of -1 law in DO time series the additional experiments covering winter seasons are highly required.

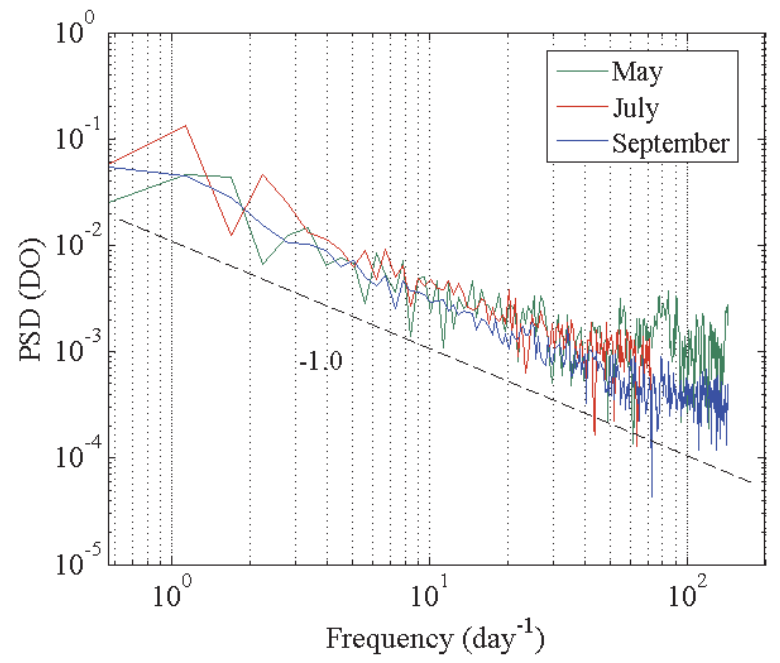

Fig. 14. The power spectral density of dissolved oxygen in the Świder River.

\section{DISCUSSION}

In this paper we analysed long-term and short-term variations of dissolved oxygen and water temperature in two rivers in order to identify factors shaping oxygen conditions in rivers and to assess the distribution of temporal variability at different frequency ranges. The results indicate that the key factors responsible for the DO variability can be observed over different timescales, from seasons to hours. Despite the differences between rivers and type of data sets, the most visible feature of the DO spectra is their overall consistency with $1 / \mathrm{f}$ scaling allowing for the integration of variations over large and small magnitudes. As pointed by Halley (1996) pink noise might be the best null model of environmental variation representing the optimal functioning of the ecosystem as it lies between white noise and the random walk. Depending on whether the statement is true, it would bear on the interpretation and modelling of ecological and evolutionary time series. In this view spectral analyses appear as a powerful tool for investigating dissolved oxygen variation of observational data.

The measurements have revealed that the anastomosing river is characterised by a less stable oxygen regime than the sandybed river. The oxygen regime of the Narew River is primarily dependent upon seasonal temperature variation, discharge and trophic status. Additionally, the limited mixing combined with high depth amplifies the daily cycle of photosynthesis/respiration and therefore, is likely to drive the variance of daily frequencies in DO concentration. Moreover, the results indicate that the highest oxygen concentrations, which are observed in early spring, result from low water temperatures, high discharge from snowmelt and flooding of the area that washes out from the system the 'old' water heavily loaded in organic matter. Furthermore, the inundation of the adjacent wetlands in spring triggers the exchange of water masses with adjacent weak channels and dead zones in an anastomosing system contributing to the delivery of organic matter to the river channels. As reported by earlier studies (Górniak and Jekatierynczuk-Rudczyk, 1998; Skorbiłowicz, 2010; Zieliński et al., 2003), the Narew River exhibits not only a distinct seasonal variability of chemical compounds, but also significant spatial diversity along its course. This manifests in particular in the local exchanges of mass and energy. For example, it has been estimated that the mean DOC $(15.88 \pm 7.07 \mathrm{mg} / \mathrm{L})$ in the Narew River decreases with the water course due to the gradual utilization by aquatic micro-organisms (Zieliński et al., 2003). Conversely, the gradual increase in nutrients concentration $\left(\mathrm{NO}_{3} 338.1 \pm 234.3 \mu \mathrm{g} / \mathrm{L}, \mathrm{NH}_{4} 211.7 \pm 110.0 \mu \mathrm{g} / \mathrm{L}\right)$ along the river course arises probably from the eutrophication by the humic substances (Górniak and Jekatierynczuk-Rudczyk, 1998). As a consequence of the heterogeneity of the Narew River, the direct effect of changing hydrological and meteorological conditions on DO variations is less meaningful in comparison to biota activity, which is a dominant factor shaping DO levels in this river. The Narew River wetlands represent a highly productive ecosystem characterised by rich biological diversity. Concurrently, it is a very susceptible river ecosystem due to the great masses of water, slow current and small diffusion rates. According to Marion et al. (2014) wetlands combine both physical and biological factors influencing wetlands processes over a wide range of spatial and temporal scales and thus are important for experimental research.

By contrast, the Świder River is unvegetated, shallow and a fast-flowing river having a sandy bed and countless river bedforms. It has relatively high fluctuations of water temperature and small oxygen deficit. The diurnal changes of DO in the Świder River correspond to the theoretical changes of water temperature and the impact of single hydrological events and meteorology is much more pronounced. Moreover, the results show that at small scale, the relation between $\mathrm{T}$ and $\mathrm{DO}$ exhibits a clockwise hysteresis, which is virtually unnoticeable at a greater timescale. As noted by Rajwa et al. (2014) hysteresis loops might reflect different shapes and sizes depending on hydrological conditions and season of the year. The presented findings conform to Genkai-Kato (2006) who explained that the presence of hysteresis results from the fact that ecosystems tend to have even more than one state or regime with selfstabilising mechanism. Therefore, the lag between succeeding states is not frequent and the changes are not easily reversible. 
These abrupt changes in the structure and function of particular system are typically expressed as a regime shift, which results from internal process or external shocks that lead to the different system behaviour (Scheffer, 2001).

In fact, hysteresis has been widely observed in hydrological studies. For example, it was applied in conceptual models such as linear reservoirs (O'Kane, 2005). The other most classical example is the hysteretic relation between water level and discharge during backwater events (Herschy, 2009; Hidayat et al., 2011). As has been well documented, single-parameter rating curves developed for particular hydrometric stations fail to reflect the real discharge under unsteady flow occurring during backwaters or flood propagation waves (Hidayat et al., 2011; Mrokowska et al., 2014; Petersen-Overleir, 2006; Rowiński et al., 2000). To compare, the studies of Moog and Whiting (1998) have shown the hysteresis between river discharge and bed load transport, whereas Williams (1989) reported hysteresis between discharge and sediment concentration rates during flood events. Basing on the observations he has distinguished five classes of relation (Fig. 14), such as: single-valued line (class I), clockwise loop (class II), counter-clockwise loop (class III), single line plus loop (class IV) and figure eight (class V). He has also stressed out that the relation is strongly influenced by many factors, such as the intensity of rainfall and its distribution, the rate and amount of runoff, travel rates and travel distances of floodwaters or sediment travel rates. However, the interpretation of hysteresis in this form seems to be somewhat subjective because some loops in Fig. 11 do not necessarily conform to the idealised geometry of the plot as presented in the Fig. 15. As pointed out by Walling and Webb (1986), the difference in the relative timing and discharge response is responsible for the hysteresis between concentration and discharge.

In the light of these considerations, any state in nature is not entirely stable at a microscopic scale, but, reversely, it fluctuates in time depending on external forces and therefore the term 'regime shift' is suitable to describe the phenomenon at a macroscopic scale (Carpenter, 2003). In this regard, further research should lead on the identification of thresholds of key variables inducing the regime shifts.

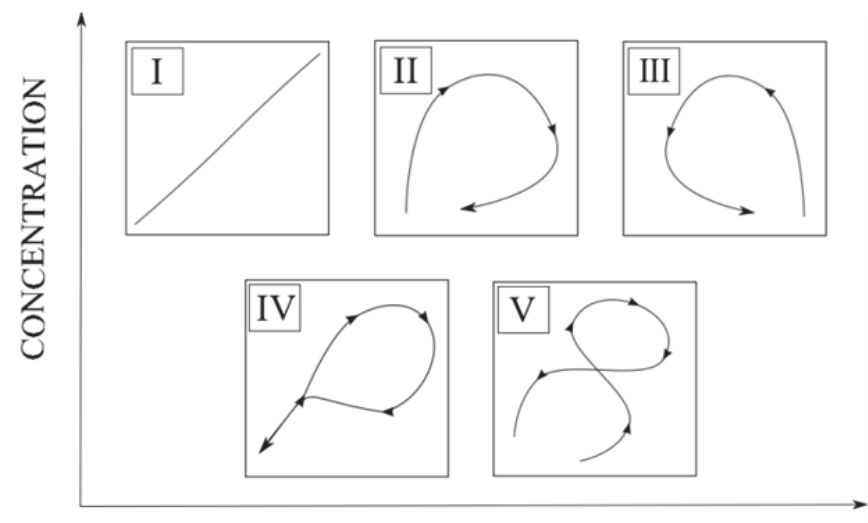

DISCHARGE

Fig. 15. Types of relation $Q-C$. Adapted from Williams (1989).

The results clearly demonstrate that physical factors such as backwaters play a substantial role in the Świder River ecosystem, and more importantly in disturbing the processes of aquatic biota. Our results suggest that the hydrology of the area has a significant influence on oxygen conditions in particular rivers and more comparative studies are necessary to understand the response of rivers to changing hydro-meteorological conditions, which is of basic and applied relevance for proper planning of wetland restoration.

\section{CONCLUSIONS}

The analysis of long-term and short-term fluctuations of dissolved oxygen and water temperature coupled with hydrometeorological background provides a valuable and unique insight into the natural variability of dissolved oxygen in rivers. Moreover, it helps to identify the key factors shaping the oxygenation of rivers and its thermal conditions over time. Power spectral analysis of DO, water temperature and water level time series have revealed a scaling region with slope -1.0 for all frequency ranges indicating increasing power at low frequencies. Moreover, one peak in the power density spectra is observed reflecting the diurnal cycle. The results show that the anastomosing river has relatively higher DO variations and less stable oxygen regime than the unvegetated river. Moreover, the changes in DO concentration in the anastomosing river correspond to season and flow conditions, and hydraulic impact on DO concentrations is less pronounced. On the other hand, the hydraulic effect on DO level plays a substantial role in the unvegetated river. Finally, short-term variability within the high-frequency data has revealed looping behaviour between water temperature and dissolved oxygen concentration, which could be missed at greater timescales. Therefore, we suggest that small scale fluctuations of DO can be analysed using hysteretic loop as it might facilitate the comparison and interpretation of field data.

Acknowledgements. This work was supported in part by the Institute of Geophysics of the Polish Academy of Sciences through the project for Young Scientists No. 500-10-16 and within statutory activities No. 3841/E-41/S/2015 of the Ministry of Science and Higher Education of Poland. Agnieszka Rajwa-Kuligiewicz gratefully acknowledges the financial support from the Interdisciplinary Polar Studies. Authors are very grateful to the two reviewers for their appropriate and constructive comments to improve the paper. Finally, the authors wish to thank the Narew National Park authorities and the Institute of Meteorology and Water Management for providing the data used in this paper.

\section{REFERENCES}

Banaszuk, H., 1996. Paleogeography. Natural and anthropogenic transformation of the upper Narew Valley. Ekonomia i Środowisko, ISBN 83-85792-30-9. (In Polish.)

Banaszuk, P., Wysocka-Czubaszek, A., 2005. Phosphorus dynamics and fluxes in a lowland river: The Narew Anastomosing River System, NE Poland. Ecol. Eng., 25, 4, 429441.

Bayley, P.B., 1991. The flood pulse advantage and the restoration of river-flood-plain systems. Regul. Rivers: Res. \& Manage., 6, 75-86.

Brown, J.H., Gillooly, J.F., Allen, A.P., Savage, V.M., West, G.B., 2004. Towards a metabolic theory of ecology. Ecology, 85, 7, 1771-1789.

Carpenter, S.R., 2003. Regime shifts in lake ecosystems: pattern and variation. In: Excellence in ecology series, 15, Ecology Institute, Oldendorf/Luhe.

Committee on Sanitary Engineering Research, 1960. Solubility of atmospheric oxygen in water. J. Sani. Eng. Div., SE7, 86, 41. 
Delworth, T., Manabe, S., 1993. Climate variability and landsurface processes. Adv. Water Resour., 16, 3-20.

Demars, B.O.L., Harper, D.M., 1998. The aquatic macrophytes of an English lowland river system: assessing response to nutrient enrichment. Hydrobiologia, 384, 75-88.

Demars, B.O.L., Harper, D.M., 2005. Distribution of aquatic vascular plants in lowland rivers: separating the effects of local environmental conditions, longitudinal connectivity and river basin isolation. Freshwater Biol., 50, 418-437.

Demars, B.O.L., Manson, J.R., Olafsson, J.S., Gislason, G.M., Gudmundsdottir, R., Woodward, G., Reiss, J., Pichler, D., Rasmussen, J.J., Friberg, N., 2011. Temperature and the metabolic balance of streams. Freshwater Biol., 56, 11061121.

Desmet, N.J.S., Van Belleghem, S., Seuntjens, P., Bouma, T.J., Buis, K., Meire, P., 2011. Quantification of the impact of macrophytes on oxygen dynamics and nitrogen retention in a vegetated lowland river. Phys. Chem. Earth, 36, 12, 479489.

Facchini, A., Mocenni, C., Marwan, N., Vicino, A., Tiezzi, E., 2007. Nonlinear time series analysis of Dissolved oxygen in the Orbetello Lagoon (Italy). Ecol. Model., 203, 339-348.

Feng, X., Kirchner, J.W., Neal, C., 2004. Spectral analysis of chemical time series from long-term catchment monitoring studies: hydrochemical insights and data requirements. Water Air Soil Pollut., 4, 221-235.

Flinn, M.B., Adams, S.R., Whiles, M.R., Garvey, J.E., 2008. Biological responses to contrasting hydrology in backwaters of Upper Mississippi River navigation pool 25. Environ. Manage., 41, 468-486.

Frieder, C.A., Nam, S.H., Martz, T.R., Levin, L.A., 2012. High temporal and spatial variability of dissolved oxygen and $\mathrm{pH}$ in a nearshore California kelp forest. Biogeosciences, 9, 3917-3930.

Genkai-Kato, M., 2006. Regime shifts: catastrophic responses of ecosystems to human impacts. Ecol. Res., 22, 214-219.

Gnauck, A., Li, B.L., Fuego, J.D.A., Luther, B., 2010. The role of statistics for long-term ecological research. In: Muller, F., Baessler, C., Schubert, H., Klotz, S. (Eds.): Long-Term Ecological Research. Between Theory and Application, Springer-Verlag, Berlin, pp. 107-129, ISBN 978-90-481-8781-2, DOI 10.1007/978-90-481-8782-9.

Goodwin, K., Caraco, N., Cole, J., 2008. Temporal dynamics of dissolved oxygen in a floating-leaved macrophyte bed. Freshwater Biol., 53, 1632-1641.

Górniak, A., Jekatierynczuk-Rudczyk, E., 1998. Water quality in the Siemianówka Reservoir (NE Poland). Int. Rev. Hydrobiol., 83, 311-318.

Gradziński, R., Baryła, J., Danowski, W., Doktor, M., Gmur, D., Gradziński, M., Kędzior, A., Paszkowski, M., Soja, R., Zieliński, T., Żurek, S., 2000. Anastomosing system of the Upper Narew River, NE Poland. Ann. Soc. Geol. Pol., 70, 219-229.

Gradziński, R., Baryła, J., Doktor, M., Gmur, D., Gradziński, M., Kędzior, A., Paszkowski, M., Soja, R., Zieliński, T., Żurek, S., 2003. Vegetation-controlled modern anastomosing system of the Upper Narew River (NE Poland) and its sediments. Sediment. Geol., 157, 253-276.

Halley, J.M., 1996. Ecology, evolution and $1 \mathrm{f}$-noise. Trends Ecol. Evol., 11, 1, 33-37.

Halliday, S.J., Wade, A.J., Skeffington, R.A., Neal, C., Reynolds, B., Rowland, P., Neal, M., Norris, D., 2012. An analysis of long term trends, seasonality and short-term dynamics in water quality data from Plynlimon, Wales. Sci. Total Environ., 434, 186-200.
Herschy, R.W., 2009. Streamflow Measurement. 3rd Edn. Taylor \& Francis, London and New York.

Hidayat, H., Vermeulen, B., Sassi, M.G., Torfs, P.J.J.F., Hoitink, A.J.F., 2011. Discharge estimation in a backwater affected meandering river. Hydrol. Earth Syst. Sci., 15, $2717-2728$.

Hocke, K., Kämpfer, N., 2009. Gap filling and noise reduction of unevenly sampled data by means of the Lomb-Scargle periodogram. Atmos. Chem. Phys., 9, 4197-4206.

Huang, Y., Schmitt, F.G., 2014. Time dependent intrinsic correlation analysis of temperature and dissolved oxygen time series using empirical mode decomposition. J. Mar. Sci., 130, 90-100.

Institute of Meteorology and Water Management (IMGW), 1983. Map of Hydrological Division of Poland. Wydawnictwo Komunikacji i Łączności, Warsaw. (In Polish.)

Junk, W.J., Bayley, P.B., Sparks, R.E., 1989. The flood pulse concept in river-floodplain systems. Canadian Special Publication of Fisheries and Aquatic Sciences, 106, 110127.

Kirchner, J.W., Feng, X., Neal, C., 2000. Fractal stream chemistry and its implications for the contaminant transport in catchments. Nature, 403, 524-527.

Kirchner, J.W., Feng, X., Neal, C., 2001. Catchment-scale advection and dispersion as a mechanism for fractal scaling in stream tracer concentrations. J. Hydrol., 254, 82-101.

Kirchner, J.W., 2005. Aliasing in $1 / \mathrm{f}^{\alpha}$ noise spectra: Origins, consequences, and remedies. Phys. Rev., 71, 066110.

Kirchner, J.W., Neal, C., 2013. Universal fractal scaling in stream chemistry and its implications for solute transport and water quality trend detection. PNAS, 110, 30, 1221312218.

Kolmogorov, A.N., 1941. Local structure of turbulence in an incompressible liquid for very large Reynolds numbers. C.R. Acad. Sci. USSR, 30, 301-305.

Lettenmaier, R.P, Hooper, E.R., Wagoner, C., Fans, K.B., 1991. Trends in stream quality in continental United States, 1978-1987. Water Resour. Res., 27, 327-339.

Mandelbrot, B.B., 1967. How long is the coast of Britain? Statistical self-similarity and the fractional dimension. Science, 156, 636-638.

Marion, A., Nikora, V., Puijalon, S., Bouma, T., Koll, K., Ballio, F., Tait, S., Zaramella, M., Sukhodolov, A., O'Hare, M., Wharton, G., Aberle, J., Tregnaghi, M., Davies, P., Nepf, H., Parker, G., Statzner, B., 2014. Aquatic interfaces: a hydrodynamic and ecological perspective. J. Hydraul. Res., 52, 6, 744-758.

Matsoukas, C., Islam, S., 2000. Detrended fluctuation analysis of rainfall and streamflow. J. Geophys. Res., 105, D23, 29165-29172.

Moog, D.B., Whiting, P.J., 1998. Annual hysteresis in bed load rating curves. Water Resour. Res., 34, 9, 2393-2399.

Mrokowska, M.M., Rowiński, P.M., Kalinowska, M., 2014. Notes on the estimation of resistance to flow during flood wave propagation. Hydrol. Earth Syst. Sc. Discus., 11, 13311-13352.

Neal, C., Reynolds, B., Rowland, P., Norris, D., Kirchner, J.W., Neal, M., Sleep, D., Lawlor, A., Woods, C., Thacker, S., Guyatt, H., Vincent, C., Hockenhull, K., Wickham, H., Harman, S., Amstrong, L., 2013. High frequency water quality time series in precipitation and streamflow: from fragmentary signals to scientific challenge. Sci. Total Environ., 434, 3-12. 
O’Connor, B.L., Judson, W.H., McPhillips, L.E., 2012. Thresholds of flow-induced bed disturbances and their effect on stream metabolism in an agricultural river. Water Resour. Res., 48, 8, W08504.

O'Kane, J.P., 2005. Hysteresis in hydrology. Acta Geophys. Pol., 53, 4, 373-283.

Pena, M.A., Katsev, S., Oguz, T., Gilbert, D., 2010. Modeling dissolved oxygen dynamics and hypoxia. Biogeosciences, 7, 933-957.

Petersen-Overleir, A., 2006. Modelling stage-discharge relationships affected by hysteresis using the Jones formula and nonlinear regression. Hydrolog. Sci. J., 51, 365-388.

Poff, N.L., Ward, J.V., 1989. Implications of streamflow variability and predictability for lotic community structure: a regional analysis of streamflow patterns. Can. J. Fish. Aquat. Sci., 46, 1805-1818.

Poff, N.L., Allan, J.D., Bain, M.B., Karr, J.R., Prestegaard, K.L., Richter, B.D., Sparks, R.E., Stromberg, J.C., 1997. The natural flow regime: a paradigm for conservation and restoration of river ecosystems. BioScience, 47, 769-784.

Rajwa, A., Rowiński, P.M., Bialik, R.J., Karpiński, M., 2014. Stream diurnal profiles of dissolved oxygen - case studies In: Proc. 3rd IAHR Europe Congress, Porto, Portugal, ISBN 978-989-96479-2-3.

Rowiński, P.M., Czernuszenko, W., Pretre, J.M., 2000. Timedependent shear velocities in channel routing. Hydrolog. Sci. J., 45, 6, 881-895.

Scheffer, M., 2001. Catastrophic shifts in ecosystems. Nature, 413, 591-596.

Schmitt, F., Dur, G., Soussi, S., Brizard, Zongo, S., 2008. Statistical properties of turbidity, oxygen and $\mathrm{pH}$ fluctuations in the Seine river estuary (France). Phys. A, 387, 6613-6623.

Skorbiłowicz, M., 2010. Concentrations of macroelements, zink and iron in water of the Upper Narew Basin, NE Poland. Polish J. Environ. Stud., 19, 2, 397-405.
Turcotte, D.L., 1997. Fractals and Chaos in Geology and Geophysics. 2nd ed. Cambridge Univ. Press, Cambridge.

Wade, A.J., Palmer-Felgate, E.J., Halliday, S.J., Skeffington, R.A., Loewenthal, M., Jarvie, H.P., Bowes, M.J., Greenway, G.M., Haswell, S.J., Bell, I.M., Joly, E., Fallatah, A., Neal, C., Williams, R.J., Gozzard, E., Newman, J.R., 2012. Hydrochemical processes in lowland rivers: insights from in situ, high-resolution monitoring. Hydrol. Earth Syst. Sci., $16,4323-4342$.

Wallis, S., 2005. Experimental study of travel times in a small stream. In: Czernuszenko, W., Rowiński, P. (Eds.): Water Quality Hazards and Dispersion of Pollutants, Springer, USA, pp. 109-120.

Walling, D.E., Webb, B.W., 1986. Solutes in river systems. In: Trudgill, S.T. (Ed.): Solute Processes. John Wiley, New York, pp. 251-327.

Williams, G.P., 1989. Sediment concentration versus water discharge during single hydrologic events in rivers. J. Hydrol., 111, 89-106.

Witt, A., Malamud, B.D., 2013. Quantification of long-range persistence in geophysical time series: conventional and benchmark-based improvement techniques. Surv. Geophys., 34, 541-651.

Whitfield, P.H., McNaughton, B., 1986. Dissolved-oxygen depression under ice cover in two Yukon rivers. Water Resour. Res., 22, 12, 1675-1679.

$\mathrm{Yu}, \mathrm{Z}$., 2006. Power laws governing hydrology and carbon dynamics in northern peatlands. Global Planet. Change, 53, 169-175.

Zieliński, P., Górniak, A., Suchowolec, T., 2003. Changes in water chemistry along the course of two rivers with different hydrological regimes. Pol. J. Environ. Stud., 12, 1, 111-117.

Received 14 May 2015 Accepted 16 September 2015 